
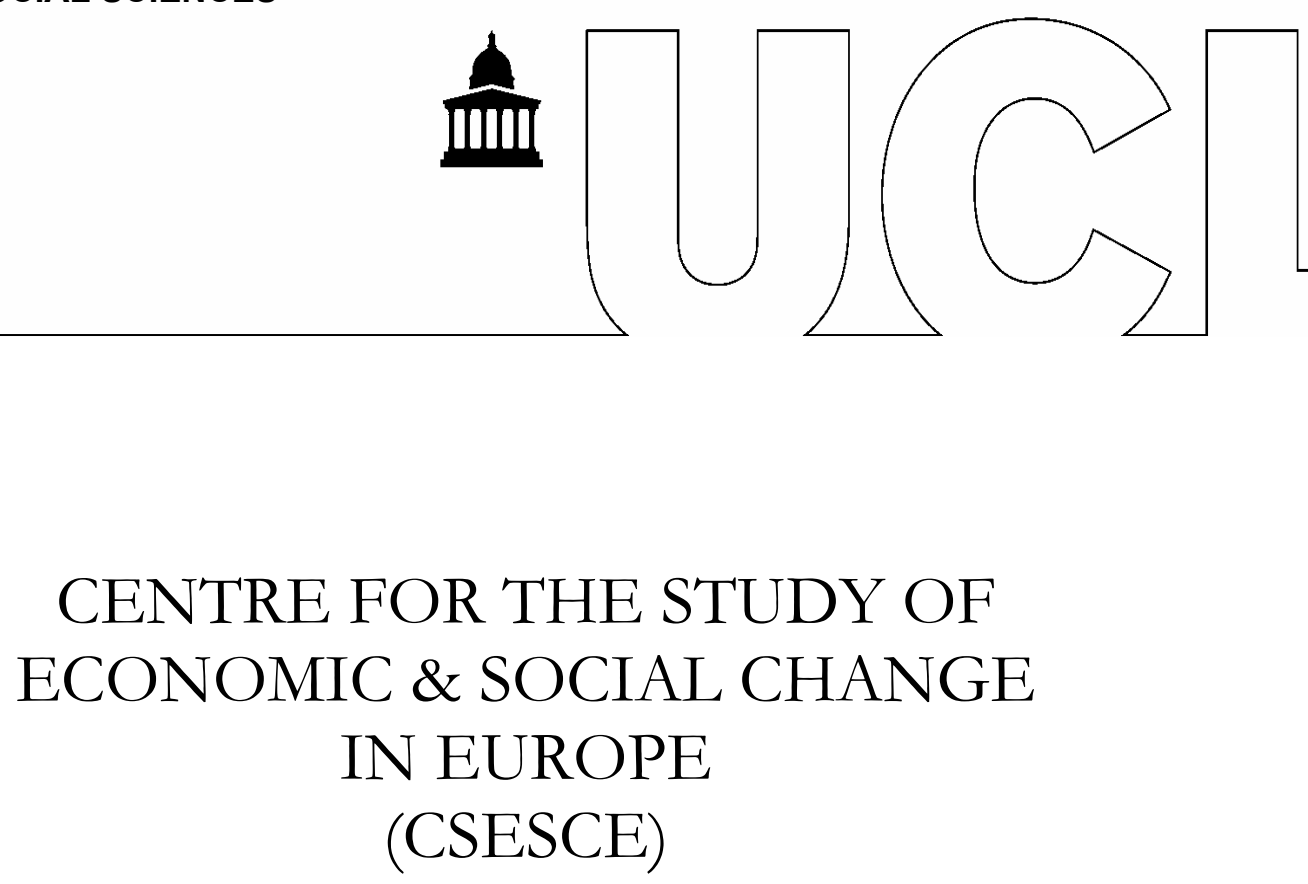

New Estimates of the Risk and Duration of Registered Unemployment in Urban Russia

Anton Nivorozhkin

Institute for Employment Research, Nuremberg, Germany anton.nivorozhkin@iab.de

Working Paper No. 60

November 2005

Centre for the Study of Economic and Social Change in Europe UCL School of Slavonic and East European Studies Gower Street London WC1E 6BT

Tel: $+44(0) 2076798519$

Fax: $+44(0) 2076798777$ Email: csesce@ssees.ucl.ac.uk 


\title{
New Estimates of the Risk and Duration of Registered Unemployment in Urban Russia
}

\author{
Anton Nivorozhkin* \\ Institute for Employment Research (IAB) ${ }^{* *}$
}

\begin{abstract}
This paper examines whether deregistration from the employment office decreases unemployment duration. The study is based on Russian individual-level data from the Public Employment Office of Rostov-on-Don combined with information from the 2000 household survey. Using a proportional hazard model, I find a significant excess in job finding rates following employment office deregistration. The predicted risk of getting a job is non-monotonic and tends to decrease at longer duration intervals. An important finding is that only $29 \%$ of the unemployed obtained a job simultaneously with deregistering from the Public Employment Office. Others continued to search for job on their own.
\end{abstract}

Keywords: Unemployment, duration, transition economics.

JEL classification: P23, J64, J68, C41.

\footnotetext{
*The author thanks Per Lundborg, Eugene Nivorozhkin, Ludmila Nivorozhkina, Ali Tasiran, Kenneth Carling, Guillaume Horny, and seminar participants at the University of Göteborg, Trade Union Institute for Economic Research (FIEF) and International Workshop "European Unemployment: Recent Developments in Duration Analysis Using Register Data" held at ZEW, Mannheim (Germany, October, 2004) for providing useful comments. The usual disclaimer applies.

** Institute for Employment Research, Regensburger Str. 104, 90327 Nuremberg, Germany, e-mail: anton.nivorozhkin@iab.de
} 


\section{Introduction}

The persistence of high unemployment is a major challenge for any society, and the problem becomes particularly acute in transition economies where unemployment was virtually non-existent fifteen years ago.

The social costs of unemployment could be reflected in terms of goods and services that were not produced, but equally important are the personal costs imposed by unemployment. Sen (1997) discusses diverse consequences of unemployment. Besides deterioration of individual economic well-being, Sen identifies at least ten distinct concerns related to unemployment. One being that excessive unemployment imposes a pressure on the social security system. Unemployment also adversely affects individual health status and contributes to the deterioration of social values. Long-term unemployment may cause physiological harm and destroy the motivation to acquire skills. ${ }^{1}$ Thus, the determinants of the probability of finding a job after a certain period of time being unemployed attract considerable attention from economists and policy makers.

Job-search theory (e.g. Mortensen, 1977; van den Berg, 1990) suggests that people are more likely to stay unemployed if they receive benefits. However, as benefits run out, individuals tend to increase job-search intensity and decrease their reservation wage. Empirical work for North America (e.g. Moffitt, 1985; Ham and Rea, 1987), Europe (e.g. van den Berg and van Ours, 1994; Carling et al., 1996), and transition economies (e.g. Lubyova and van Ours, 1999; Miklewright and Nagy,

\footnotetext{
${ }^{1}$ Recent studies for Russia show that unemployment is one of the major factors affecting household welfare, child health and property crimes (Fedorov and Sahn, 2003; Klugman and Kolev 2001; Andrienko, 2001). Moreover, in 1998 the expenditures on labor market programs in Russia amounted to 921 million US\$, which corresponded to $0.2 \%$ of the country's GDP (O'Leary et al., 2001)
} 
1996) often found negative or inverse U-shape duration dependence, with clear impact of benefit exhaustion. ${ }^{2}$

Studies of the determinants of unemployment duration in Russia are limited and could be categorized according to the definition of unemployment and datasources used in the analysis. Foley (1997), Grogan and van den Berg (2001) define unemployed according to the ILO guidelines and use the Russian Longitudinal Monitoring Survey (RLMS) database which is representative for Russia. A problem related to the usage of RLMS is that the exact unemployment duration is often unknown and the number of unemployment benefit claimants is small. ${ }^{3}$ Thus, the conclusions of the above papers on the duration dependence and impact of unemployment insurance are uncertain. Denisova (2002) and Nivorozhkin et al. (2004) investigate the determinants of unemployment duration of individuals registered with the Public Employment Office (PEO) using state unemployment register data. Neither study contains precise information on reasons for leaving unemployment, treating all exits from the employment office as transitions to a job. The results of the studies on unemployment duration are summarized in Table 1.

Table 1: Summary of the empirical findings for Russia

\begin{tabular}{|c|c|c|c|}
\hline Study & Data & $\begin{array}{l}\text { Definition of } \\
\text { Unemployment }\end{array}$ & $\begin{array}{l}\text { Duration dependence } \\
\text { (exit to a job if not otherwise stated) }\end{array}$ \\
\hline Foley (1997) & $\begin{array}{lll}\text { RLMS } & 1994 \quad- \\
1996 & & -\end{array}$ & ILO & Inverse $-\mathrm{U}$ shape relationship \\
\hline $\begin{array}{l}\text { Grogan and } \\
\text { van den Berg } \\
(2001)\end{array}$ & $\begin{array}{l}\text { RLMS } \\
1998\end{array}$ & $\begin{array}{lr}\text { ILO; Discourage } \\
\text { workers; } & \text { Unpaid } \\
\text { leave; } & \text { Wage } \\
\text { arrears } & \end{array}$ & $\begin{array}{l}\text { The exit rate is highest between } 6-12 \\
\text { months, reaching the peak between } 9 \\
\text { and } 12 \text { months }\end{array}$ \\
\hline $\begin{array}{l}\text { Nivorozhkin et } \\
\text { al. }(2004)\end{array}$ & $\begin{array}{l}\text { Registry data, } \\
\text { Rostov-on-Don } \\
\text { city } \\
1997-1998\end{array}$ & $\begin{array}{l}\text { Registered } \\
\text { unemployed }\end{array}$ & $\begin{array}{l}\text { Negative duration dependence for exit } \\
\text { from the PEO with employment and } \\
\text { inverse -U shape relationship for exit } \\
\text { from the PEO without employment }\end{array}$ \\
\hline $\begin{array}{l}\text { Denisova } \\
(2002)\end{array}$ & $\begin{array}{l}\text { Registry data, } \\
\text { Voronezh region } \\
1996-2000\end{array}$ & $\begin{array}{l}\text { Registered } \\
\text { unemployed }\end{array}$ & $\begin{array}{l}\text { Positive duration dependence for } \\
\text { exit from the PEO }\end{array}$ \\
\hline
\end{tabular}

\footnotetext{
${ }^{2}$ See Atkinson and Micklewright (1991), Bean (1994), and Meyer (1995) for literature surveys on the impact of unemployment insurance in OECD countries.

${ }^{3}$ See Grogan and van den Berg (2001) for the discussion of problems related to spell construction in RLMS database.
} 
The objective of this study is to present new evidence on the determinants of unemployment duration. Based on the data collected in the survey in the big industrial city of Rostov-on-Don, combined with the information obtained from the registries of the PEO I present new evidence on the determinants of unemployment duration among benefit recipients. The paper fills the unemployment duration knowledge gap by presenting results of the first follow-up survey of unemployed individuals registered with the Russian PEO during the year 2000. Similar surveys have been conducted in a number of other countries (e.g. O'Leary et al., 2001; Micklewright and Nagy, 1999: and Bring and Carling, 2000; van den Berg et al., 2004).

Using the results of the follow-up survey I demonstrate that registration with the PEO ended with a transition to a job in only $29 \%$ of the cases; $71 \%$ of the unemployed continued to search for a job after deregistration. Relying only on exit information from the PEO would produce a deficient picture of flows to employment. By taking into account the large differences between the outflow from the PEO and the inflow to employment, I address the question of whether the individual job search intensity changes following deregistration from the PEO.

The difference between outflow from unemployment registries and inflow to work are not truly unique to Russia. Micklewright and Nagy (1999) report that a majority of the unemployed deregistered from the employment office in Hungary due to the exhaustion of benefits and not because they found a job.

The next section presents an overview of the institutional setup of the Russian labor market. Section 3 describes the data used in the analysis. Section 4 presents the results of estimation and Section 5 concludes the paper. 


\section{Unemployment in Russia: Background}

The Russian economic decline throughout most of the 1990s led to a rise in unemployment. To respond to this problem the Public Employment Office (PEO) was organized in Russia in the beginning of 1990s. The PEO is the main component of the social safety net for the unemployed and provides unemployment benefits and offers active labor market programs.

Unemployment benefits are awarded to individuals who have left employment regardless of the reason. The benefits are calculated as a percent of the average wage during the proceeding three months if the individual had a paid full-time job during at least 26 weeks out of the last 12 months. The amount of unemployment benefits during the first three months equals $75 \%$ of the wage received at the previous job, $60 \%$ during the next four months and from then on $-45 \%$. Individuals who do not qualify are entitled to receive minimum benefits equal to $20 \%$ of the regional subsistence equivalent. ${ }^{4}$ In any case, the benefits cannot exceed the regional subsistence equivalent and cannot be lower than 100 Rubles per month. The duration of benefit payments should not exceed 12 cumulative months during a period of 18 calendar months. For individuals entering the labor market for the first time, those without a profession, and the long-term unemployed the duration of benefit payments should not exceed six cumulative months in an 18 calendar month period. ${ }^{5}$

The benefit payments may be interrupted for a period of three months if an individual refuses to participate in public works or refuses to accept two "suitable" job offers. Moreover, the period of benefit entitlement is shortened by three months and credits towards retirement stop to accumulating. The job is considered "suitable" if it matches the profession of the unemployed and provides the subsistence equivalent for

\footnotetext{
${ }^{4}$ In the fourth quarter of 2003 the survival equivalent in the Rostov region was set to, 1961 Rubles.
} 
those who had a wage equal or above the subsistence equivalent prior to becoming unemployed. $^{6}$

The definition of unemployment provided by the PEO of Russia has been criticized (Grogan and van den Berg, 2001, Kapelushnikov, 2002). The criticism has focused mainly on the fact that the population of registered unemployed individuals reflects the population of unemployed defined according to the ILO guidelines poorly. ${ }^{7}$ However, the large differences in the levels of unemployment are not truly unique for Russia. Such differences persist in a large number of countries (e.g. ILO, 1995; Hussmanns 1994, 2001). The major limitation of the information supplied by the PEO is that the composition of the population of registered unemployed may depend on the rules and conditions governing eligibility to unemployment benefits. Thus the results of this study should be viewed as being conditional on the current legislation. Yet, datasets supplied by the PEO have three major virtues. First of all they are inexpensive and easy to acquire, since they are a side product of the functioning of the PEO. Second, the data on benefit claimants can be collected quickly and frequently. Finally, information from the PEO registries is the only source of systematic information on unemployment in Russian cities.

This study is based on data on individuals who registered with the Rostov-onDon PEO and received the status of unemployed in 2000. Rostov-on-Don is one of the largest cities in Russia with a population of over one million. ${ }^{8}$ It is the center of the fifth largest Russian region, Rostov oblast'. The city has acquired extra political and

\footnotetext{
${ }^{5}$ Several recent amendments were introduced to the law, but they do not apply to our study.

${ }^{6}$ If individual has not been working for more than a year or does not have a profession she can be offered any type of job.

${ }^{7}$ During the period 1992-2000, unemployed registered at the PEO were on average only $23 \%$ of the unemployed defined according to the ILO concept. The reasons for a disparity between reported levels of unemployment are discussed in Kapelushnikov (2002), Nivorozhkin (2003) and Tchetvernina et al. (2001).

${ }^{8}$ A national unemployment register does not exist in Russia.
} 
economic importance since it became the capital of the Southern Federal District, organized as a result of the recent federal-system reform. According to official statistics in 1999, the index of physical volume of GDP in the Rostov region rose by 9.5\% and continued to increase at an accelerating rate in 2000 (Russian Statistical Agency, 2002). The regional unemployment rate was $14.9 \%$, which was higher than the Russian average of $10.5 \%$.

The study of the determinants of unemployment duration in one city raises a question about the representativeness of the results for the rest of Russia. Indeed, Russia shows marked regional economic differentiation. However, with the exception of Moscow, the results are likely to apply to other big industrial cities because of a common set of factors affecting labor markets in these cities. First of all, a uniform legislative framework determines rules of registration with the PEO. Moreover, large cities are usually similar in having a diversified industrial structure, with one or two large industrial enterprises dominating. Large cites also have a well-developed educational and training infrastructure. Finally, the preserved system of population registration and under-developed housing markets discourage labor mobility creating stagnant unemployment pools in the cities. Thus, labor market processes in large industrial cities are likely to be similar and can be addressed by studying only one representative city.

\section{Data}

The PEO had 17,270 individuals registered as open unemployed in 2000. In order to trace unemployed individuals up to the point of employment a follow-up house-to-house survey was organized. ${ }^{9}$ The original sample consisted of 2,000

\footnotetext{
${ }^{9}$ The support of the Institute of Independent Social Policy (Grant No. SP-02-2-12, Ford Foundation) in data collection is gratefully acknowledged.
} 
randomly selected individuals. The main advantage of the survey was the possibility to collect information about the individuals' job positions after deregistration from the PEO. The survey was implemented in September, 2002. The respondents were asked about their labor market status after leaving the PEO and about the precise date of finding a new job. ${ }^{10}$

The overall survey response rate was $77.3 \%$. There were two main reasons for non-response: refusal to let the interviewer in or refusal to answer the questions. In some cases individuals had moved to new locations without providing new addresses.

The information about employment collected during the follow-up survey was, combined with the characteristics of the unemployed individuals, available in the PEO database. Social-demographic information on registered individuals (age, gender, marital status, number of children, and dependents, etc.), and professional characteristics (working experience, previous wage, education, profession, and qualification) were included.

\section{Empirical application}

Transition data analysis or duration modeling was used to model the impact of various socio-economic characteristics on the unemployment duration among individuals registered with the PEO. Comprehensive overviews of duration models are presented in Kiefer (1988), Lancaster (1990), and Tasiran (1995). More, recent developments are summarized in van den Berg (2001).

\footnotetext{
${ }^{10}$ The data lacked information on secondary employment, but this should not pose a problem when considering the short-term effect, since it is unlikely that individuals would find primary and secondary jobs simultaneously. There are several different estimates of secondary employment in Russia. According to official figures in 2000 , only $1.8 \%$ of labour-force survey respondents reported having a secondary job. The results of the RLMS study indicate that $4-11 \%$ of workers have secondary employment, however.
} 
Individuals transiting to early retirement were removed from the analysis. The reason is that these individuals are likely to behave differently regarding obtaining a regular job and are likely to correctly forecast the destination of their transition. Moreover, we excluded all individuals participating in active labor market programs. This leaves us with 1,099 observations.

\subsection{Non-parametric estimation}

A useful start in the application of transition data analysis is to consider simple non-parametric estimators of survival and hazard functions. The Kaplan-Meier plot of survival function (see Figure 1) measures how many people remain in the unemployment pool (survived) as time passes.

Unemployment was measured in days beginning from the date of registration and ending with the date of employment. The spell is considered to be right-censored if an unemployed individual was still unemployed at the end of our observation period.

Figure 1: Survival probability

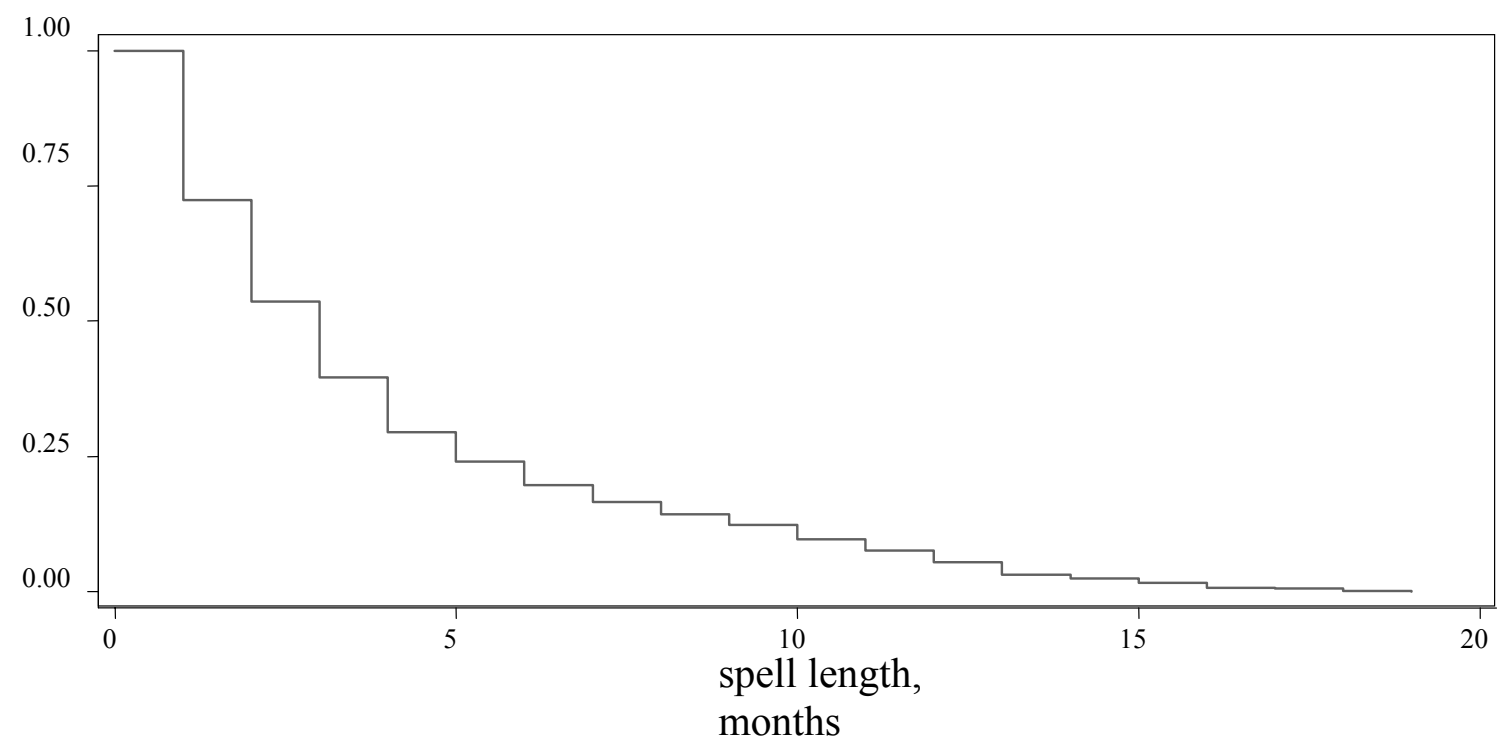


The product limit estimate of hazard function can be derived from this plot. It shows the number of people who left unemployment relative to the total number of individuals unemployed at each point in time. Non-parametric estimates of hazard function are presented in Figure 2. A "rapid" increase in hazard rate in the interval up to three months can be observed. In the interval from three months and onwards, the function monotonically decreases.

Figure 2: Transition rates to a job

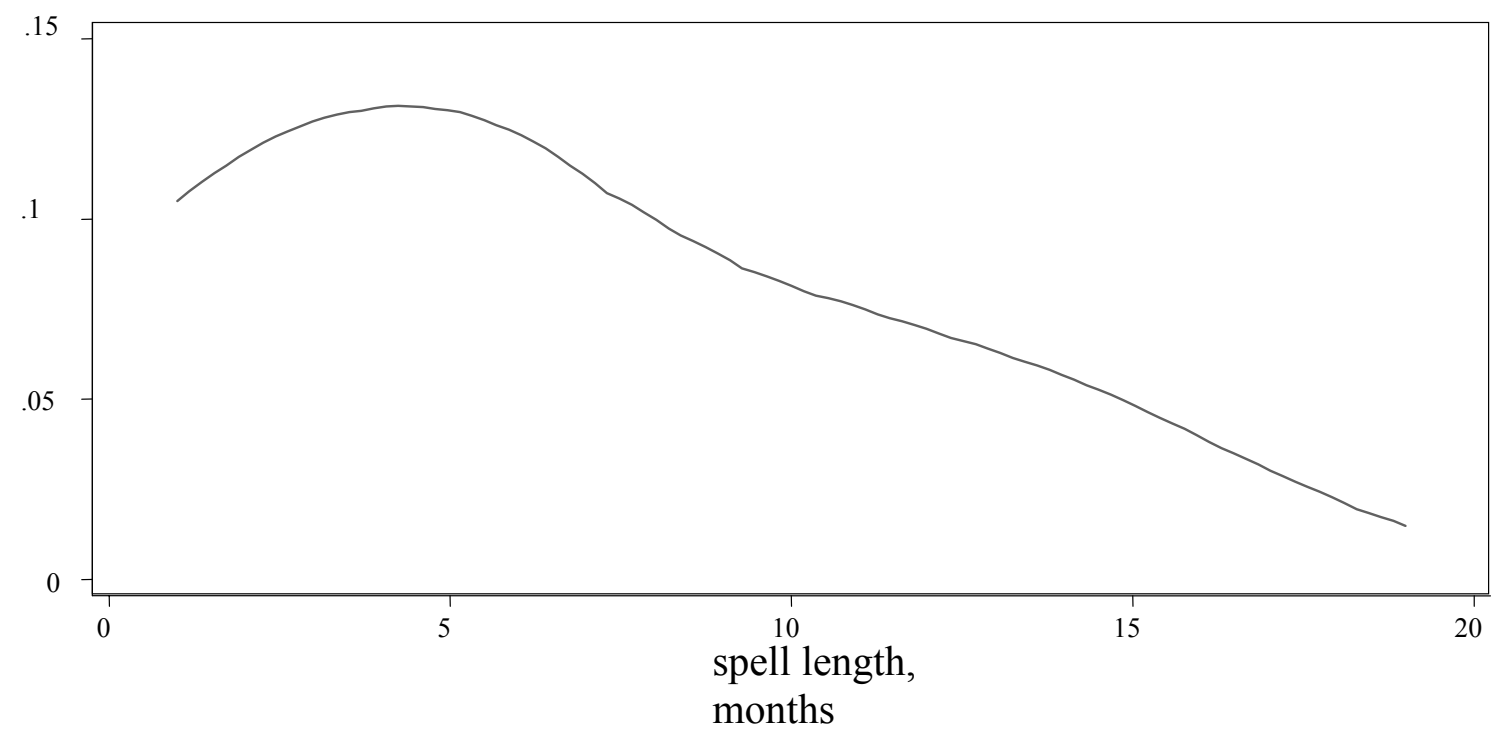

Among unemployed with complete duration, 94\% experienced transition to employment within one year from registering with the PEO. The fluctuation of the hazard function in the duration interval exceeding one and a half years is explained by the presence of a relatively small group of individuals most of whom did not find a job under the period of investigation. The results indicate that mean complete duration of unemployment is 109 days. Duration is shorter for those who left the PEO simultaneously with obtaining a job relative to those who left the PEO without a job (85 versus 121 days). 


\subsection{Semi-parametric estimation}

Discussion of the duration of registered unemployment often assumes that all recipients deregister from the PEO for the reason of obtaining a job. This ignores the possibility that individuals may continue to be unemployed and search for job after deregistration from the PEO. To analyze the changes in the intensity of the job search among those who left the PEO without employment a time-varying covariate as an indicator variable representing registration with the PEO was constructed. This variable (Search with the PEO) takes a value of 1 when an individual searched for a job with the PEO, and 0 when she had left the PEO and continued to search for a job on her own. In order to understand the construction of the dataset, it may be appropriate to represent it graphically (see Figure 3).

\section{Figure 3: Event space}

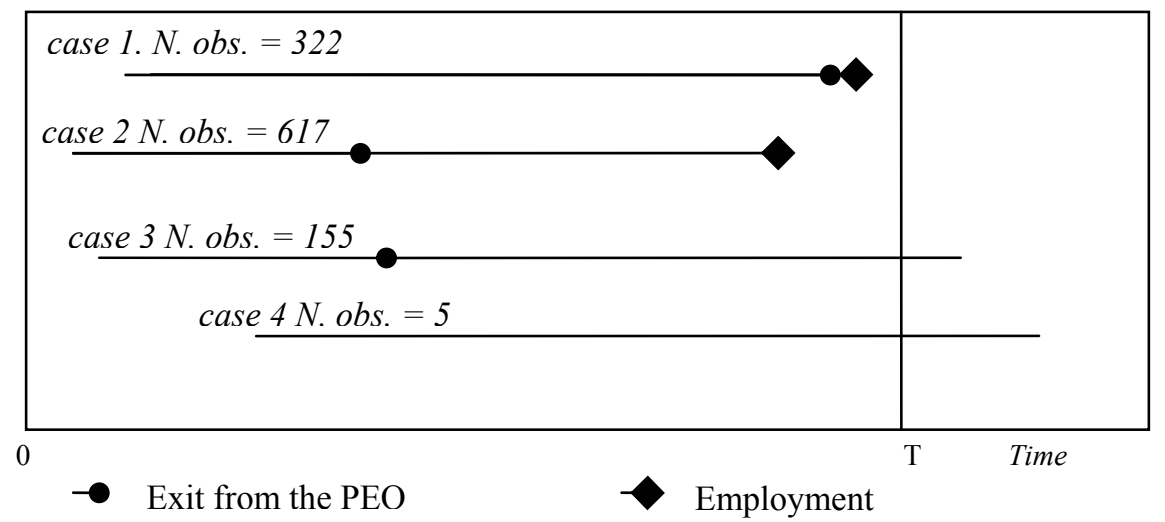

In the dataset 939 individuals (Case 1 and Case 2) found a job during the period of investigation. The difference between the cases is that in Case 1 individuals deregistered from the PEO because they found a job and in Case 2 individuals continued to search for a job after deregistration from the PEO. In Cases 3 and 4, 160 individuals failed to find a job during the period of investigation. However, in Case 3 
individuals deregistered from the PEO and continued to search for a job without extra assistance from the PEO. It is also evident from the figure that only $29 \%$ of the individuals left the PEO with employment; the others continued to search for jobs on their own. ${ }^{11}$

If deregistration from the PEO has a positive impact on the individual job search intensity, then the coefficient of the variable Search with the PEO would have a negative sign; otherwise it would be positive.

A number of studies (e.g. Blossfeld, Hamerle and Mayer, 1989; Lancaster, 1990; and Tasiran, 1995) point out that estimating a model that incorporates timevarying covariates may be complicated for two reasons. First, it may be difficult to separate the effect of time-dependent covariate from possible duration dependence. Second, time-varying variables may be endogenous to the process of finding a job.

The first problem may be solved by a careful interpretation of time-varying covariates, taking into account their interaction with time. ${ }^{12}$ The problem of endogenously defined covariates is harder to solve. Lancaster (1990) suggests an example of a marital status covariate in a model of job tenure where one cannot rule out the possibility that the covariate is neither endogenous nor exogenous. The same logic can be applied to this model. Assuming for now that the decision to search for a job with or without the PEO is completely choice driven, it can be said that the path of the covariate Search with the PEO and the information that an individual is still unemployed at $t+d t$ may or may not help predict the course of the covariate in the time interval $(t, t+d t)$. Thus, the covariate could either be endogenous or exogenous for duration of unemployment. Moreover, rules that govern deregistration from the

\footnotetext{
${ }^{11}$ Note also that out of 617 individuals who left the PEO and continued to search for jobs on their own, $76 \%$ stayed unemployed for more than one extra week.

${ }^{12}$ To control for time dependency an interaction term of the variable Search with the PEO and logged duration was included.
} 
PEO indicate that deregistration is not necessarily a choice variable. In fact, it may take place before the exhaustion of a benefit entitlement period. For example, the rule about two "suitable" job offers forces a large number of individuals to leave the PEO involuntarily. Such individuals do not necessary transit to employment; on the contrary most of them continue to search for jobs on their own after deregistering from the PEO.

\subsection{Means of variables used in the analysis}

Table 2 presents definitions of variables and their means, stratified for two subgroups: those who found jobs while being registered with the PEO and those who continued to search for jobs after deregistering from the PEO.

Variables reflecting the socio-demographic and professional status of unemployed, describing the circumstances of entering the PEO, and unemployment benefits received were used in the analysis. The following socio-demographic characteristics were used: gender, age, marital status, and number of children. These characteristics are likely to influence the behavior of unemployed individuals. Level of education, professional experience, and profession prior to starting unemployment spell were captured by a set of dummy variables. Additional dummies to control for whether the individual received wage above or below the city average as opposed to not having a wage were included. These variables aim to proxy for the type of job that the PEO officer may offer to unemployed individuals. Finally, dummy variables for minimum benefits and disadvantage status awarded by the PEO were included. ${ }^{13}$

\footnotetext{
${ }^{13}$ Disadvantage variable captures different groups of unemployed who are by law considered to be deprived and thus may receive special treatment from the PEO officers.
} 
Table 2: Means of variables used in the analysis

\begin{tabular}{lccc}
\hline Variable & Total sample & $\begin{array}{c}\text { Obtained a job } \\
\text { while been in the } \\
\text { PEO }\end{array}$ & $\begin{array}{c}\text { Searched for job } \\
\text { after left the PEO }\end{array}$ \\
\hline Male & 0.34 & 0.36 & 0.33 \\
Age $\leq 20$ & 0.16 & 0.18 & 0.15 \\
$20<$ Age $\leq 30$ & 0.30 & 0.32 & 0.28 \\
$30<$ Age $\leq 40$ & 0.18 & 0.15 & 0.19 \\
$40<$ Age $\leq 50$ & 0.25 & 0.25 & 0.26 \\
Age $>50$ & 0.11 & 0.11 & 0.12 \\
One child & 0.22 & 0.20 & 0.23 \\
More than two children & 0.07 & 0.06 & 0.08 \\
Married & 0.44 & 0.43 & 0.46 \\
University education & 0.34 & 0.31 & 0.35 \\
Technical secondary & 0.27 & 0.26 & 0.27 \\
General secondary & 0.21 & 0.29 & 0.18 \\
Only primary & 0.18 & 0.14 & 0.19 \\
No work experience & 0.25 & 0.31 & 0.23 \\
No profession & 0.19 & 0.25 & 0.16 \\
Blue collar worker & 0.32 & 0.29 & 0.34 \\
White collar worker & 0.49 & 0.46 & 0.50 \\
From out of the labor force & 0.62 & 0.61 & 0.62 \\
Wage is less than city average & 0.2 & 0.19 & 0.20 \\
Wage is above than city average & 0.15 & 0.13 & 0.15 \\
Minimum Benefit & 0.60 & 0.67 & 0.57 \\
Disadvantage & 0.06 & 0.05 & 0.06 \\
Number of observations & 1099 & 327 & 772 \\
\hline
\end{tabular}

\subsection{Model selection}

A single destination model of exit to a job is estimated. Compared to earlier studies of duration of registered unemployed (Denisova, 2002; Nivorozhkin et al., 2004) the estimates account for actual date of employment as opposed to deregistration from the PEO. The analysis of the withdrawal from the labor force is omitted. $^{14}$

\footnotetext{
${ }^{14}$ Nesporova (1999) indicates that in transition countries individuals withdraw themselves from the labor market because they are unable to find suitable jobs that would give them reasonable remuneration. Such individuals may be classified rather as discouraged long-term unemployed than as individuals in out of the labor force. This claim can be supported by the analysis of RLMS data. Grogan and van den Berg (2001) report that in 1995, 85\% of non-workers who reported that they did not search for jobs in the month preceding the interview also reported that they wanted jobs.
} 
Two issues are of special concern in the application of duration analysis. The first is the way to control for possible unobserved heterogeneity and the second is the choice of distribution of the hazard function.

A model may lead to the wrong conclusion about the estimated hazard rate and probability of survival when unobserved heterogeneity is neglected. Controlling for unobserved heterogeneity is therefore important (e.g. Lancaster, 1990; and van den Berg, 2001). In order to control for possible heterogeneity, the model assuming parametric form of gamma distributed unobserved heterogeneity was estimated. ${ }^{15}$

One can also estimate several duration models by assuming different distributions for baseline hazard functions, and as a result arrive at a different conclusion about the shape of the hazard. It is therefore important to test the appropriateness of distributional assumption. The model was selected according to the Akaike Information Criterion (AIC). ${ }^{16}$ The criterion is based on the modified version of the maximum-likelihood criterion, where the likelihood of each model is penalized by the number of parameters estimated in the model. According to the test the preferred model should produce the smallest AIC value. AIC provides a convenient framework to discriminate among different distributional assumptions, but does not justify the appropriateness of the model itself. Table 3 presents the results from estimating of the AIC. Our estimates indicate that the piecewise constant exponential model has the lowest score among all estimated models and thus should be preferred. ${ }^{17}$ The piecewise constant exponential model is also preferable if sudden changes in hazard rate, for example due to the changes in the benefit levels, are expected. The hazard rate is assumed to be constant within time intervals but is

\footnotetext{
${ }^{15}$ See Gutierrez (2002) for an overview of duration model estimation in Stata.

${ }^{16}$ Here AIC is defined as $A I C=-2 / N^{*}\left(L_{m}\right)+2 k_{m} / N$, where $L_{m}$ is the likelihood of the model $m, k_{m}$ is the parameters estimated in the model $\mathrm{m}$, and $N$ is the number of observations.

${ }^{17}$ Similar results are obtained when applying the Schwarz Criterion was applied.
} 
allowed to differ among time intervals. The hazard intervals are defined to be constant within nine intervals $[0,60),[60,120), \ldots,[480,540),[540, \infty)$ and the indicators are constructed so that the baseline interval (for which all indicators are equal to zero) is the interval $[540, \infty)$.

Table 3: Overview of the Akaike Information Criterion Scores

\begin{tabular}{lccc}
\hline Distribution & Log likelihood & AIC & rank \\
\hline & & & \\
Exponential & -1189.69 & 2.20 & 3 \\
Weibull & -1185.21 & 2.20 & 2 \\
Lognormal & -1277.32 & 2.36 & 4 \\
Log/logistic & -1526.12 & 2.82 & 5 \\
Piecewise exponential with 9 60 days pieces & -1043.85 & 1.96 & 1 \\
\hline
\end{tabular}

\subsection{Results of estimation}

Table 4 presents two specifications of the piecewise constant exponential model with unobserved heterogeneity. ${ }^{18}$ The results are robust to the model specification. ${ }^{19}$

Being male shortens expected time in unemployment relative to females. The results presented by Foley (1997) support these findings. The author found that women tend to have longer unemployment spells, and that this effect is even more pronounced for married women. Grogan and van den Berg (2001) indicate the opposite relationship; they report shorter survival time (earlier exit from unemployment) for women.

The age coefficients imply that older individuals are disadvantaged compared to younger counterparts, although in the specification which includes time-varying covariates this relationship is insignificant for individuals younger than twenty and for

\footnotetext{
${ }^{18}$ The results of the estimation without unobserved heterogeneity are available on request. Accounting for unobserved heterogeneity is important; the likelihood ratio test for the absence of unobserved heterogeneity suggests that the hypothesis that the unobserved heterogeneity parameter is equal to zero could not be accepted.
} 
the 30-40 cohort. In terms of education, only individuals with general secondary education are found to obtain jobs faster than individuals with only primary education. Concerning the household composition, neither the fact that the individual is married nor that the individual has children impacted on the hazard rate significantly. ${ }^{20}$

Summarizing our results on the social-demographic profile of unemployed, one may conclude that males and individuals with general secondary education have higher risk of transiting to a job. However, this conclusion needs several clarifications. There is a large body of literature aiming to explain gender-based differences. Some studies attribute the higher incidence and longer duration of unemployment of females to the issue of discrimination. Rhein (1998) shows that, in Russia, women have become increasingly unable to secure their employment and are more likely to become unemployed. On the other hand, the longer unemployment duration of females may also be explained by the inherent conditions of the urban labor market. There are simply less vacancies for females on the labor markets of big industrial cities. If there are relatively few female positions on the market than it may be reasonable for women to search for job less intensively (Grogan and van den Berg, 1999). This hypothesis is supported by the results of the survey of benefit claimants undertaken by the PEO of Rostov-on-Don in 1999. According to the survey in $8 \%$ of the cases employers, who place the job offer into the vacancy bank of the PEO, rejected applicant due to unsuitable gender (Nivorozhkin et al., 2004).

Among the previous employment characteristics, only the wage earned at the last place of work affects hazard rate significantly. Individuals who reporting zero wages are likely to leave unemployment faster. There are two possible closely linked

\footnotetext{
${ }^{19}$ Several specifications including interaction terms of various socio-economic characteristics and interactions with benefit levels were estimated, but none of them was statistically significant.
} 
explanations to this fact. First, individuals who report zero wages, reference category, are more likely to find "suitable jobs" at the PEO vacancy bank. Second, individuals who report non-zero wage at the last place of work are likely to have higher reservation wage and thus stay unemployed longer. Entitlement to a minimum benefit within a period of registration with the PEO is found to be insignificant, suggesting that benefit provision has no direct impact on the risk of exit to a job. One should also keep in mind that previous research (Nivorozhkin et al., 2004) indicates that individuals who are entitled to a minimum benefit are more likely to leave the PEO sooner. Provision of benefits has some impact on the duration of registration with the PEO, but is unlikely to have impact on the duration of unemployment.

I also included a variable aiming to capture individuals coming from outside the labor force or belonging to a disadvantaged group. In the estimation these variables are found to be negative, thus decreasing the risk of transition from unemployment (although statistically insignificant).

The purpose of including the time-varying variable Search with the PEO is to access the individual job search intensity inside and outside the PEO. The coefficient Search with the PEO, which takes the value 1 when an individual is registered with the PEO and 0 otherwise, indicates that an individual's job search intensity tends to increase if the individual deregisters from the PEO and continues to search for a job on her own. Formally, a negative sign on the variable Search with the PEO indicates that deregistration from the PEO increases the hazard of exit from unemployment. An important issue in our interpretation of the job search intensity is its interaction with time. The interaction term Search with the PEO with logged duration (Search with the $P E O \times \log D U R)$ was included in the estimation. In the estimation this variable turns

\footnotetext{
${ }^{20}$ It should be noted that information on the composition of households is limited; there is no
} 
out to be statistically insignificant, thus I conclude that duration itself does not influence our conclusion on the impact of Search with the PEO.

To check for robustness of the results I labeled all individuals who obtained a job within 7 days after deregistration from the PEO as employed at the moment of leaving the PEO. This had no significant effect on the results. ${ }^{21}$

In the estimation a baseline hazard could vary within a period of 18 months, but was held constant during each 60 day interval.

A comparison of the models with and without unobserved heterogeneity reveals that duration dependency is affected by the presence of unobserved heterogeneity. Lancaster (1990) shows that ignoring unobserved heterogeneity when it is important would result in overestimation of the degree of negative duration dependency or underestimation of positive duration dependency.

The hazard rate to a job appears to be non-monotonic. The sharp increase on interval from 60 to 180 days may be explained by two competing hypothesis. During this period the most significant reduction of unemployment benefits occurs, thus a lot of individuals may be motivated to increase the job search intensity. Another explanation is that at early periods of unemployment individuals are more likely to receive job offers from the PEO. Thus, the increase in hazard rate may be due to the process of filling the available vacancies available with the PEO vacancy bank.

information on a size of a household and head of a household. It is also not clear whether spouse is unemployed.

${ }^{21}$ Results are available on request. 
Table 4: Estimation of piece-wise constant exponential model with unobserved heterogeneity

\begin{tabular}{|c|c|c|c|c|}
\hline \multirow[t]{2}{*}{ Variable } & \multicolumn{2}{|c|}{$\begin{array}{c}\text { Includes time-varying } \\
\text { covariate }\end{array}$} & \multicolumn{2}{|c|}{$\begin{array}{l}\text { Excludes time-varying } \\
\text { covariate }\end{array}$} \\
\hline & Coefficient & St.D. & Coefficient & St.D. \\
\hline Male & 0.442 & $(0.149)^{* * *}$ & 0.503 & $(0.115)^{* * *}$ \\
\hline Age $\leq 20$ & 0.380 & $(0.362)$ & 0.689 & $(0.275)^{* *}$ \\
\hline $20<$ Age $\leq 30$ & 0.653 & $(0.259)^{* *}$ & 0.707 & $(0.206)^{* * *}$ \\
\hline $30<$ Age $\leq 40$ & 0.420 & $(0.272)$ & 0.490 & $(0.216)^{* *}$ \\
\hline $40<$ Age $\leq 50$ & 0.413 & $(0.243)^{*}$ & 0.354 & $(0.195)^{*}$ \\
\hline One child & 0.111 & $(0.185)$ & -0.110 & $(0.145)$ \\
\hline More than two children & -0.248 & $(0.284)$ & -0.278 & $(0.223)$ \\
\hline Married & 0.088 & $(0.158)$ & 0.154 & $(0.123)$ \\
\hline University education & 0.168 & $(0.238)$ & -0.003 & $(0.181)$ \\
\hline Technical secondary & -0.013 & $(0.226)$ & -0.196 & $(0.171)$ \\
\hline General secondary & 0.627 & $(0.232)^{* * *}$ & 0.179 & $(0.174)$ \\
\hline No work experience & 0.172 & $(0.320)$ & 0.304 & $(0.232)$ \\
\hline No profession & 0.409 & $(0.312)$ & -0.062 & $(0.227)$ \\
\hline Blue-collar worker & -0.026 & $(0.179)$ & 0.078 & $(0.138)$ \\
\hline From out of the labor force & -0.161 & $(0.170)$ & -0.014 & $(0.132)$ \\
\hline Wage is less than city average & -0.447 & $(0.229)^{*}$ & -0.893 & $(0.185)^{* * *}$ \\
\hline Wage is greater city than & -0.557 & $(0.260)^{* *}$ & -1.069 & $(0.212)^{* * *}$ \\
\hline Minimum Benefits & 0.197 & $(0.177)$ & -0.217 & $(0.139)$ \\
\hline Disadvantaged & -0.100 & $(0.307)$ & 0.165 & $(0.235)$ \\
\hline Search with the PEO & -3.586 & $(0.237)^{* * *}$ & - & - \\
\hline Search with the $\mathrm{PEO} \times \log D U R$ & -0.053 & $(0.055)$ & - & - \\
\hline \multicolumn{5}{|c|}{ Piece-wise constant hazard rates days } \\
\hline $0-60$ & 3.814 & $(1.046)^{* * *}$ & 3.803 & $(1.051)^{* * *}$ \\
\hline $61-120$ & 4.308 & $(1.039)^{* * *}$ & 4.318 & $(1.030)^{* * *}$ \\
\hline $121-180$ & 4.377 & $(1.036)^{* * *}$ & 4.176 & $(1.022)^{* * *}$ \\
\hline $181-240$ & 3.930 & $(1.039)^{* * *}$ & 3.960 & $(1.022)^{* * *}$ \\
\hline $240-300$ & 3.958 & $(1.039)^{* * *}$ & 4.187 & $(1.019)^{* * *}$ \\
\hline $301-360$ & 3.971 & $(1.039)^{* * *}$ & 4.220 & $(1.020)^{* * *}$ \\
\hline $361-420$ & 4.346 & $(1.034)^{* * *}$ & 4.630 & $(1.017)^{* * *}$ \\
\hline $421-480$ & 4.043 & $(1.044)^{* * *}$ & 4.145 & $(1.030)^{* * *}$ \\
\hline $481-540$ & 3.088 & $(1.087)^{* * *}$ & 3.224 & $(1.081)^{* * *}$ \\
\hline $\ln \left(\sigma_{u}^{2}\right)$ & 2.20 & $(0.143)^{* * *}$ & 1.05 & $(0.16)^{* * *}$ \\
\hline Constant & -6.358 & $(1.110)^{* * *}$ & -8.721 & $(1.09)^{* * *}$ \\
\hline Log-likelihood & \multicolumn{2}{|c|}{-1043.85} & \multicolumn{2}{|c|}{-1841.71} \\
\hline $\mathrm{N}$ of subjects & \multicolumn{2}{|c|}{1099} & \multicolumn{2}{|c|}{1099} \\
\hline
\end{tabular}

Notes: Standard errors in parentheses: $*$ significant at $10 \% ; * *$ significant at 5\%; $* * *$ significant at $1 \%$. Coefficients indicate variables' effects on the hazard function, a positive coefficient increasing the probability of exit, and thereby decreasing expected duration. Reference categories: Female; Older than 50; No children; Single; Primary education; Some work experience; White-collar worker; Previously employed; No wage prior to registration; Receive non-minimum benefit. 


\section{Conclusion}

Leaving the PEO without obtaining a job is one of the most common ways to exit the unemployment register in urban Russia. The analysis sheds light on what happens after deregistration and thus is important for the analysis of unemployment duration, labor market flows, and government policy. The results found for Russia may have implications for other Central and Eastern European counties with similar unemployment insurance system. Micklewright and Nagy (1999) show that in Hungary, a majority of unemployed individuals deregister from the employment office without obtaining a job.

The rules and regulations governing benefit entitlement induce a majority of individuals to leave the PEO before they are able to find a job. The results show that $71 \%$ of individuals leave the PEO without employment. This finding raises concerns and calls for a formal evaluation of the job-search programs offered to unemployed individuals. Deregistration of individuals from the PEO increases the hazard of exit from unemployment. Given that I control explicitly for the duration dependency of the hazard, the results point to potential disincentive effects of being registered with the PEO. These disincentives are likely to be a combination of the effects of monetary transfers and social benefits provided by the registration. The latter perhaps play a greater role given the relatively low magnitude of unemployment benefits and the fact that the size of the benefits does not appear to affect the hazard of exit to employment in a significant manner. This finding may in turn suggest that a reduction of benefits may not the produce expected increase in job-finding rates for the majority of unemployed.

A positive impact of deregistration from the employment office on the probability to find a job was found in other countries. Cockx and Ries (2004) found 
for Belgium that termination of unlimited payments of benefits, for selected groups of unemployed, increased the job-finding rates by up to $25 \%$. Indirect evidence is presented in Lalive et al. (2005), in which the authors found that benefit sanctions significantly reduce unemployment duration.

Taking into account the fact that the hazard to a job is non-monotonic and declining in the long run, indicating a negative effect of time on individual probability of leaving unemployment, it may be worthwhile to identify groups expected to stay unemployed longer and provide them with proper incentives to search for jobs in the earlier stages of unemployment.

From a policy standpoint, an important issue that deserves future investigation is the impact of deregistration from the PEO on individual living standards. More research on this topic is warranted. 


\section{References}

Andrienko, Y. (2001), "Understanding the crime growth in Russia during the transition period: A criminometric approach", HSE Economic Journal, Vol. 5(2), pp. 194-220.

Atkinson, A. and Micklewright, J. (1991), "Unemployment compensation and labour market transitions: A critical review", Journal of Economic Literature, Vol. 29(4), pp. 1679-727.

Bean, C.R. (1994), "European unemployment: A survey", Journal of Economic Literature, Vol. 32(2), pp. 573-619.

Blossfeld, H.-P., Hamerle, A., and Mayer, K. (1989), Event history analysis, Hillsdale Erlbaum.

Bring, J, and Carling K. (2000), "Attrition and misclassification of drop-outs in the analysis of unemployment duration”, Journal of Official Statistics, Vol. 16(4), pp. 321-30.

Carling, K., Edin P.-A., Harkman, A., and Holmlund B. (1996), “Unemployment duration, unemployment benefits, and labor market programs in Sweden", Journal of Public Economics, Vol. 59(3), pp. 313-34.

Cockx, B., and Ries, J. (2004), “The exhaustion of unemployment benefits in Belgium: Does it enhance the probability of employment?", Institute for the Study of Labor (IZA), IZA Discussion Papers 1177.

Denisova, I. (2002), "Staying longer in unemployment registry in Russia: Lack of education, bad luck, or something else?", New Economics School, Working paper.

Fedorov, L., and Sahn, D. (2004), “Socio-Economic determinants of children's health in Russia: Estimating a dynamic health production function”, Cornell Food and Nutrition Policy Program, Working Paper N. 135.

Foley, M. (1997), "The determinants of unemployment duration in Russia", University of Michigan, Working Paper N. 81. 
Grogan, L., and van den Berg, G.J. (2001), "The duration of unemployment in Russia", Journal of Population Economics, Vol. 14(3), pp. 549-68.

Gutierrez, R.G. (2002), "Parametric frailty and shared frailty survival models", Stata Journal 2(1), pp. 22-44.

ILO (1995), World Labour Report, International Labour Organization.

Ham, J.C. and Rea, S.A. (1987), “Unemployment insurance and male unemployment duration in Canada", Journal of Labor Economics, Vol. 5(3), pp. 325-53.

Hussmanns, R. (1994), International standards on the measurement of economic activity, employment, unemployment and underemployment, Labour statistics for a market economy: Challenges and solutions in the transition countries of Central and Eastern Europe and the former Soviet Union, Budapest: Central European University Press in association with the International Labour Office.

Hussmanns, R. (2001), Unemployment statistics: Important issues, Working Paper, Training Workshop on Labour Market Information and Analysis, Harare, Zimbabwe.

Kapelushnikov, R. (2002), “Obschaja i registrirujamaja bezrabotitsa: v chem. Prichiny razriva?", State University, Higher School of Economics, Working paper, WP3/2002/03,

Klugman, J., and Kolev, A. (2001), "The role of the safety net and the labor market on falling cash consumption in Russia: 1994-96. A quintile-based decomposition analysis", The Review of Income and Wealth, Vol. 47(1).

Kiefer, N.M., (1988), "Economic duration data and hazard functions", Journal of Economic Literature, Vol. 26(2), pp.646-79 
Lalive, R., van Ours J.C., and Zweimüller J. (2005), "The effect of benefit sanctions on the duration of unemployment", Journal of the European Economic Association, forthcoming.

Lancaster, T. (1990), The econometric analysis of transition data, Cambridge University Press, Cambridge.

Lubyova, M. and van Ours, J.C. (1999), "Unemployment duration of job losers in a labour market in transition, The Economics of Transition, Vol. 7(3), pp. 66586.

Meyer, B.D. (1995), "Lessons from the U.S. unemployment insurance experiments", Journal of Economic Literature, 33(1), pp. 91-131.

Micklewright, J., and Nagy, G. (1996), Labour market policy and the unemployed in Hungary, European Economic Review, Vol. 40(3), pp. 819-28.

Micklewright, J., and Nagy, G. (1999), Living standards and incentives in transition: The implications of exhausting UI entitlement in Hungary, Journal of Public Economics 73(3), 297-320.

Moffit, R. (1985), "Unemployment insurance and the distribution of unemployment spells", Journal of Econometrics, Vol.28(1), pp. 85-101.

Mortensen, D.T. (1977), "Unemployment insurance and job search decisions", Industrial and Labor Relations Review, Vol. 30(4), pp. 50517.

Nesporova, A. (1999), Employment and labour market policies in transition economies, International Labour Office, Geneva.

Nivorozhkin E., Nivorozhkina L., and Nivorozhkin, A. (2004), Leaving unemployment with state assistance: Evidence from Russia, Current Politics and Economics in Russia, Eastern and Central Europe, Vol. 19(4), pp.75-98. 
Nivorozhkin, E. (2003), "Registered unemployment in Russia: Does it matter?", Russian Economy: The month in review, Bank of Finland, Institute for Economies in Transition.

O’Leary C., Nesporova A., Samodorov A. (2001), Manual on evaluation of labour market policies in transition economies, Geneva, ILO.

Rhein, W. (1998), "The feminization of poverty: Unemployment in Russia", Journal of International Affairs, Vol. 52(1), pp. 351-366.

Russian Statistical Agency 2002, “Russian Regions 2001”, Goskomstat

Sen, A. (1997), Inequality, unemployment and contemporary Europe, International Labour Review, Vol. 136(2), pp155-71.

Tasiran, A.C. (1995), Fertility dynamics, spacing and timing of births in Sweden and the United States, North-Holland.

Tchetvernina, T., Moscovskaya, A., Soboleva, I., and Stepantchikova, N. (2001), Labour market flexibility, employment and social security: Russian Federation, International Labour Office.

van den Berg, G.J. (1990), "Nonstationarity in job search theory", Review of Economic Studies, Vol. 57, pp. 255-277.

van den Berg, G.J. and van Ours J.C. (1994), “Unemployment dynamics and duration dependence in France, The Netherlands and the United Kingdom”, Economic Journal, Vol. 104, pp. 432-43.

van den Berg G.J. (2001), Duration models: specification, identification, and multiple durations, in: J.J. Heckman and E. Leamer, eds. Handbook of Econometrics, North-Holland. 
van den Berg, G. J., Lindeboom, M. and Dolton, P. (2004), "Survey non-response and unemployment duration", , Institute for the Study of Labor (IZA), IZA Discussion Paper No. 1303. 
59 De-industrialisation and the Post-Communist Transition: Rowthorn and Well's Model Revisited

Tomasz Mickiewicz and Anna Zalewska

58 Upgrading Russian Enterprises from the Value Chain Perspective: the Case Study of Tube \& Pipe, and Furniture Sectors

Svetlana Avdasheva, Igor Budanov, Victoria Golikova and Andrei Yakovlev

57 The Promotion of Innovation in Slovenia through Knowledge Transfer from Higher Education Institutions to SME's

Will Bartlett and Vladimir Bukvič

56 Reconstitution of Post-Soviet Ex-State Enterprises into Russian Business Firms under Institutional Weaknesses

Yuko Adachi

55 Post-Communist Recessions Re-examined

Tomasz M. Mickiewicz

$54 \quad$ Leadership and Corruption in Russia, 2000-2004

Alena V. Ledeneva

$53 \quad$ Foreign Direct Investment and Restructuring in the Automotive Industry in Central and East Europe

Slavo Radosevic and Andrew Rozeik

52 Financial Performance of Groups of Companies in Poland against the Background of Historical Determinants and Knowledge Management Procedures Applied

Jan Chadam and Zbigniew Pastuszak

$51 \quad$ Are the EU New Member States Fiscally Sustainable? An Empirical Analysis Mariusz Jarmuzek

50 Growth Expectations of Business Owners: Impact of Human Capital, Firm Characteristics and Environmental Transition

Ruta Aidis and Tomasz Mickiewicz

49 Firms' capabilities related to the economic system: cases from Ukraine and Russia

Gustavo Rinaldi

\section{CSESCE Working Papers}

48 Ambiguity of Social Networks in Post-Communist Contexts

Alena V. Ledeneva

47 Privatisation, Corporate Control and Employment Growth: Evidence from a Panel of Large Polish Firms, 1996-2002'

Tomasz Mickiewicz, Christopher J Gerry and Kate Bishop

46 Wage Bargaining, Privatisation, Ability to Pay, and Outside Options - Evidence from Hungary

Janos Köllő and Tomasz Mickiewicz

45 Informal Practices in Changing Societies: Comparing Chinese Guanxi and Russian Blat

Alena V. Ledeneva

44 The Estonian Organizations - The Subjects of Transformation'

Maaja Vadi and Harry Roots

43 Revisiting Consumption Smoothing and the 1998 Russian Crisis Christopher J Gerry and Carmen A Li

42 Insurance Company Financial Management by Optimising Premium Level: the case of Poland.

Adam Sliwinski 